\title{
Effectiveness of Domestic Reverse Osmosis Units for Removal of Fluoride and Hardness for Drinking Purposes in Chronic Kidney Disease of Unknown Etiology (CKDu) Affected Areas in Anuradhapura
}

\author{
Perera K.K.W. ${ }^{1 *}$, Bandara N.J.G.J. ${ }^{1}$ and Jayaweera M.W. ${ }^{2}$ \\ ${ }^{1}$ Department of Forestry and Environmental Science, University of Sri Jayewardenepura, Sri Lanka \\ ${ }^{2}$ Department of Civil Engineering, University of Moratuwa, Sri Lanka \\ *kushanikumudumaleeperera@gmail.com
}

\begin{abstract}
The hypothesis having excessive fluoride and hardness levels in ground water in combination is said to have been associated with the onset of CKDu. Provision of good quality drinking water devoid of fluoride and hardness to levels less than nephrotoxic levels would be considered of paramount importance. In this respect, several types of water filters have been introduced to CKDu affected areas of which RO units are the most popular filters. Hence, this research aims at investigating the effectiveness of domestic RO units in removing fluoride and hardness levels reported in CKDu affected areas under different climatic conditions for a period covering dry and wet seasons. Two monsoons and the $2^{\text {nd }}$ inter monsoon were simulated in the laboratory and the removal of fluoride and hardness by the RO unit were evaluated according to the drinking water guidelines.
\end{abstract}

Northeast monsoon was subdivided into extreme wet and wet to dry periods. Hardness and fluoride concentrations in the raw water during above periods were $110 \mathrm{ppm}$ and $578 \mathrm{ppm}$ and fluoride concentrations were $0.52 \mathrm{ppm}$ and $2.93 \mathrm{ppm}$ respectively. In the above periods hardness values obtained in the permeate were $12 \mathrm{ppm}$ and $24 \mathrm{ppm}$ and the fluoride was completely removed during extreme wet period and $0.15 \mathrm{ppm}$ fluoride was observed in wet to dry period. In the $2^{\text {nd }}$ inter monsoon, hardness and fluoride concentrations in raw water were $1032 \mathrm{ppm}$ and $7 \mathrm{ppm}$ respectively and in the permeate $40 \mathrm{ppm}$ hardness and $0.39 \mathrm{ppm}$ of fluoride were observed. All the above fluoride and hardness values in the permeate do not comply with the required drinking water guidelines. Southwest monsoon was subdivided in to three periods namely extreme dry, dry and dry to wet. In extreme dry period hardness and fluoride in raw water were $1230 \mathrm{ppm}$ and $15.5 \mathrm{ppm}$ respectively. In the permeate hardness concentration varied from 48 ppm-184 ppm and fluoride concentrations varied from $0.19 \mathrm{ppm}-$ $1.67 \mathrm{ppm}$. At the latter stage both the fluoride and hardness values have exceeded the required drinking water guideline values. This happen when all the adsorption sites of the filter unit get saturated with the increase of the raw water concentration and then excess amount of water constituents will pass through the RO membrane. Flow rate was dropped from 0.24 litres/min to 0.03 liters/min during these periods implying that the membrane of the unit has started to get clogged. As the performance of the RO unit depends on the initial constituent's concentration in the raw water, according to this study people can use RO unit for a period of 6 months without getting clogged.

Keywords: Chronic kidney disease of unknown etiology, Fluoride, Hardness, Reverse osmosis

Proceedings of the International Forestry and Environment Symposium 2016, Department of Forestry and Environmental Science, University of Sri Jayewardenepura, Sri Lanka. 